\title{
Plastic Deformation, Mechanical and Adhesive Properties of Bio-Plastic Material
}

\author{
Hamdi Abdulhamid Raghs ${ }^{1}$ \\ ${ }^{1}$ Mechanical Engineering Department, Faculty of Engineering, University of Karabuk, Turkey \\ e-mail: hamdiraghis@yahoo.com
}

\begin{abstract}
Given the added need for eco-friendly material, environmental scientists are constantly on the look-out for new solutions. In this respect, biodegradable polymer proved to be a promising one. The Selfix material, being a bioplastic, is biodegradable and, unlike other plastic products, can be considered feasible for the industry as a smart material capable of biodegrading at the end of its life cycle. Using Selfix, waste paper can be re-used, thus eliminating the need for recycling and helping to reduce the $\mathrm{CO}_{2}$ emissions. The present paper develops 3D models with Selfix material to offer benefits such as easy-cutting and sticking properties in a way that can be educational for children. We examine the mechanical properties of this material using tensile testing, laser-cutting, CNC milling, surface roughness and also scanning electron microscope or SEM.
\end{abstract}

Keywords: Scanning Electron Microscope (SEM); Computer Numerical Control (CNC); heat shape mould; mechanical properties of bio plastic; waste management; adhesives behaviour; biodegradable polymers.

\section{INTRODUCTION}

With the new environmental policies and legislation implemented in different parts of the EU, landfills are being slowly eliminated in this part of the world. Up to now, the main ways to deal with waste included incineration, energy recovery comprising gasification pyrolysis and composition, as well as separating and reusing as a second option. Lately, numerous governments have introduced new innovative ways as regards the environment $[1,2]$.

Therefore, with the aim to keep the environment safe and regulate the use of natural sources, certain countries have started to introduce new policies. Among these, the UK has come up with a series of tools and approaches such as trading systems, environmental taxation, and voluntary agreements intended for large companies to reduce paper and cardboard waste, for example. There, paper and cardboard, which can be collected, recycled and reused easily, constitute the material that is predominantly left over as waste in commerce $[3,4]$.
In line with these efforts, a new material created by the Selfix Technology Company in UK may be used as recycled paper and cardboard for producing $3 \mathrm{D}$ objects and boxes. The present research attempts to demonstrate the Selfix technology as well as find further solutions for similar environmental problems and examine the potential effects [5].

Selfix is produced from a combination of polylactide (PLA), Poly-3 hydroxybutyrate (PHB), cellulose, and starch $\left(\mathrm{C}_{6} \mathrm{H}_{10} \mathrm{O}_{5}\right)$, all available in large quantities from natural sources and having the ability to absorb humidity. One can obtain biodegradable adhesives with novel adhesion behavior from these materials when exposed to water, with no eventual harmful impacts on the environment. In detail, a smart polymer comes in the shape of a thin plastic sheet, which shows adhesive behavior when wet by water, and can be used to glue cardboards, paper and wood. Interestingly enough, Selfix can be shaped into any desired form or dimensions. As a non-toxic biodegradable product, it is also characterized by a 
low melting temperature and begins to soften up at about $60^{\circ} \mathrm{C}$. The applications for this material are numerous, namely for home use, in prototyping, jewellery, toy-making, mould formation, and many others. The Selfix material can be turned into mould within two minutes - that is when it begins to gradually harden. The material, though, can be heated again and again for continuous work. Selfix is ideal for creative work and adding entertainment to education, regardless of the target group, apart from the applications in $2 \mathrm{D}$ and $3 \mathrm{D}$ design and modelling $[5,6]$.

The samples of Selfix (Figure 1) are examined and tested using different techniques in the following sections.

\section{TECHNIQUES AND PROCEDURES}

The first experiment involved a tensile test as a means to determine the mechanical properties and behaviors of this material using axial loading. The tensile test was applied to stretch a sample to the breaking point and to see the extent of such stretch elongation. In this way, it was possible to calculate the stress $(\sigma)$ from the load

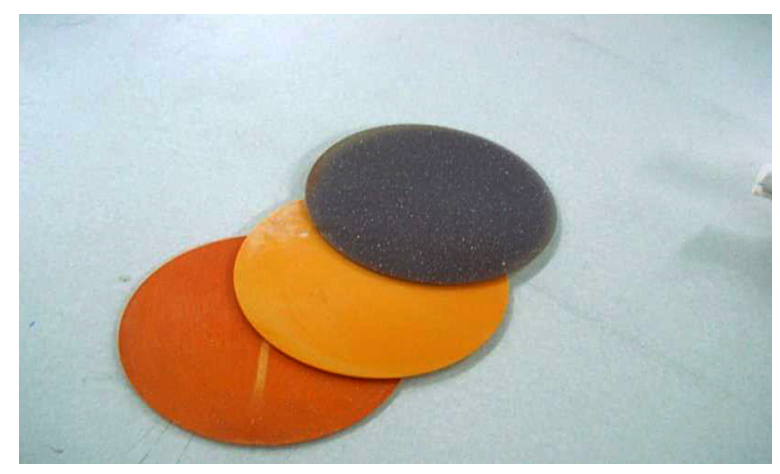

Fig. 1. Selfix material disk
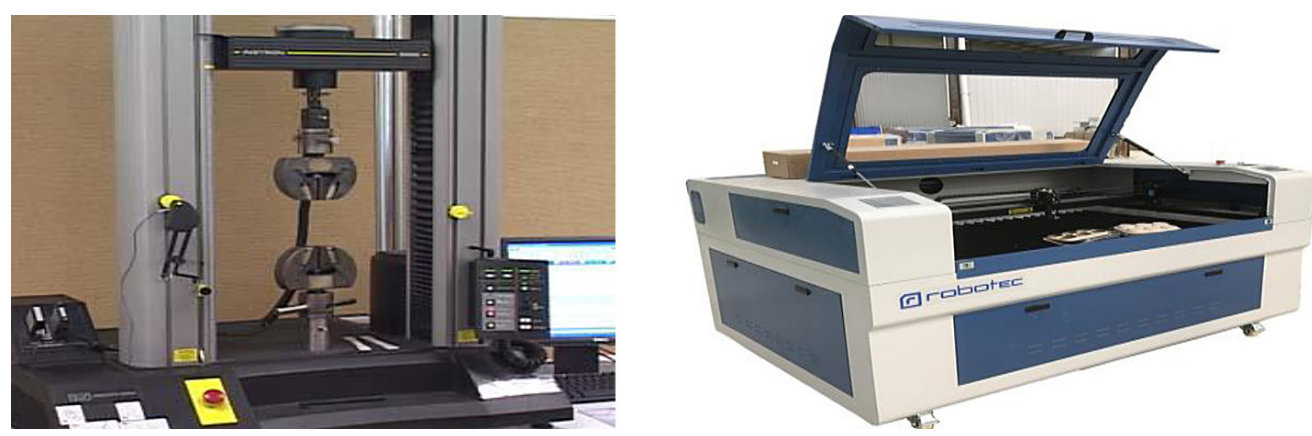

Fig. 2. Tensile testing machine \& laser cutting machine and the strain $(\varepsilon)$ from the extension in the form of plotting nominal stress against nominal strain or as true stress against true strain. These relations vary in each graph and are controlled by a computer software for monitoring and registering the outcomes $[7,8,9]$.

Here, like many other cases and materials, laser cutting exposes the material to heat from a laser beam controlled with CorelDraw software [10].

Apart from the laser, CNC milling - again a common technique in various complex operations such as slot cutting, planning, drilling, rebating, routing, etc. - operates on 3-axes and comprises a surface moving horizontally along the $\mathrm{X}$ and $\mathrm{Y}$ axes, and vertically along the $\mathrm{Z}$ axes for depth [11, 12].

The surface roughness measurements were conducted to identify the kind of interaction between the material and the surroundings as well as to predict the mechanical performance, ideal roughness, and surface qualities in the machined material $[13,14]$.

Here, again, these estimates were carried out using software for the centre-line average (CLA) and Roughness average (Ra). For this purpose, a surface profilometer was used with a contact stylus to achieve the maximum accuracy and efficiency. Once the surface analysis was complete, other factors were also determined through the comparison of all the peaks and valleys with the mean line $[15,16]$.

The scanning electron microscope (SEM), using a targeted beam of high-energy electrons, produces an array of signals on the surface of the samples. As an outcome of the interaction between the electrons and the surface of the sample, these signals contain the data pertaining to outer morphology or texture, chemicals available, crystalline formation, and the orientation of the material within the specimen $[17,18]$. 

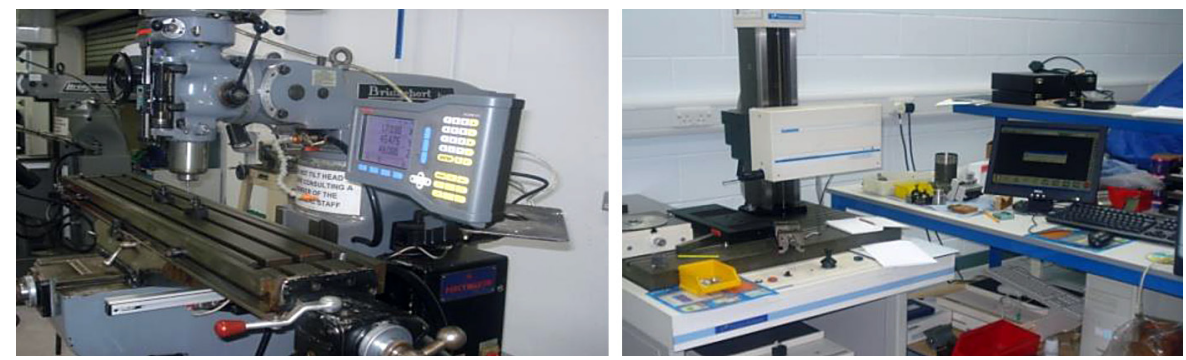

Fig. 3. CNC milling machine \& surface roughness measurement

\section{RESULTS AND DISCUSSION}

\section{Results of tensile testing for specimens from selfix plastic material}

As stated earlier, in the lab, the CorelDraw software was employed to make a drawing of the Selfix plastic specimens for subsequent laser cutting and tensile testing. These were carried out to reveal certain mechanical and adhesive characteristics. Figure 5 and 6 shows the specimens from a Selfix plastic disk and the sample broken after test.

The initial results point to the stress and strain curve as well as the mechanical properties of the specimens for Selfix plastic disk (Table 1 and Graph 1).

Figures 7 and 8 show the sheets cut from the Selfix which are bound together with no difficulty by simply wetting the material and sticking them together, ultimately to determine the adhesive qualities. The second result was related to the stress and strain curve as well as the specimen properties of the sheets put together by wetting (Table 2 and Graph 2).

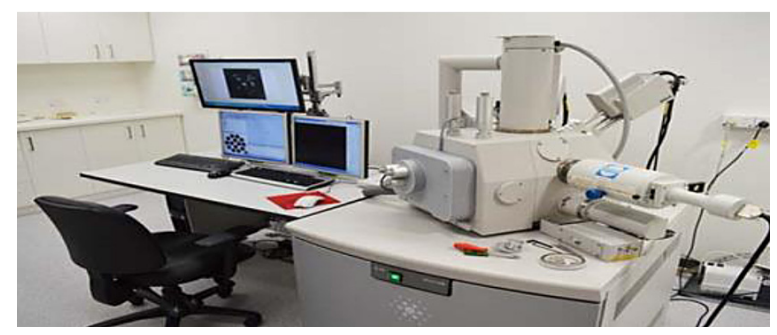

Fig. 4. Scanning electron microscope in the lab

Fgures 9 and 10 show sheets of specimen when glued to cardboard and upon completing the tensile tests to reveal the adhesive qualities. Here, a break can be spotted in the cardboard without any tear signs on the Selfix plastic sheet.

Finally, the third related result concerns stress and strain curves as well as the adhesive qualities of the samples stuck on cardboards. Accordingly, one can observe that the Selfix plastic sample maintains strength better than the cardboard. With additional improvements, this material is expected to become even more durable; hence, other applications and extended use in different areas is possible. The Table 3 highlights the precise
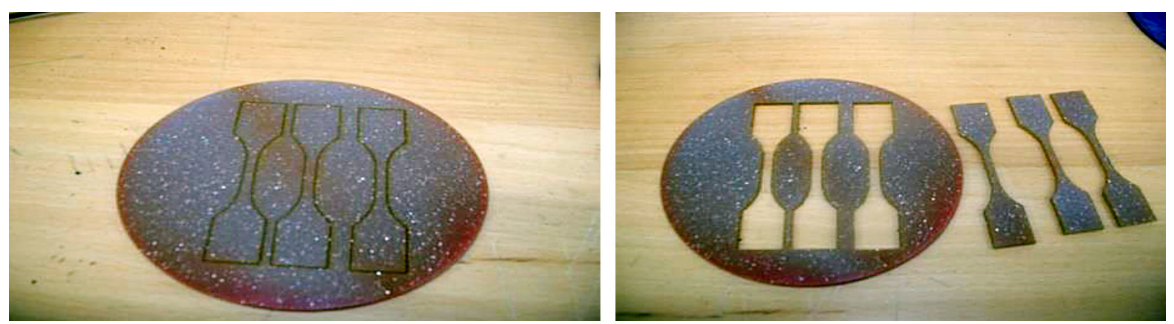

Fig. 5. Cut specimens from Selfix plastic disk by laser cutting
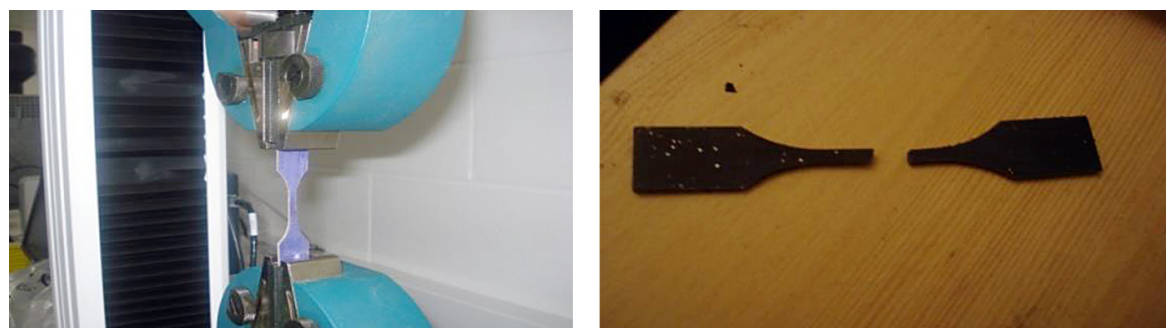

Fig. 6. The specimen in machine $\&$ the specimen broken after test 
dimensions of the Selfix plastic sheet(s) stuck to cardboard and used for tensile testing (Graph 3).

\section{Analysis of tensile test results}

In the Graphs 1, 2 and 3 of tensile test, all specimens show a relative and acceptable bonding strength. Since Selfix is an adhesive, numerous forms of testing can be carried out to measure its quality; among them, peel testing is best applied to determine adhesive properties. Here, the strength in bonding between the bio polymers available in various mixtures with cardboard helps with high levels of resistance against pressure, causing the bond to last longer than expected. As per the curves, one can observe various characteristics, all due to the sheet being highly elastic and modulus and the disk being low in these regards given flexibility and collapse factors.

\section{Results of laser cutting on selfix material}

For laser cutting, various settings were tested to find the best one for the Selfix plastic material. On the basis of our observations, the ideal speed

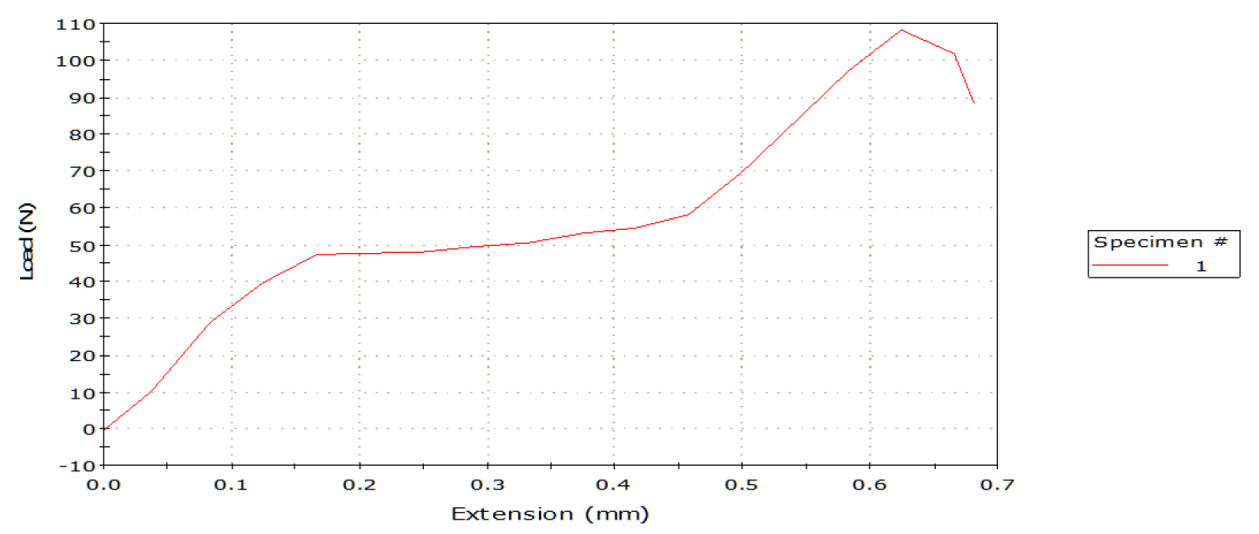

Graph 1. Extension vs load specimen for Selfix plastic disk

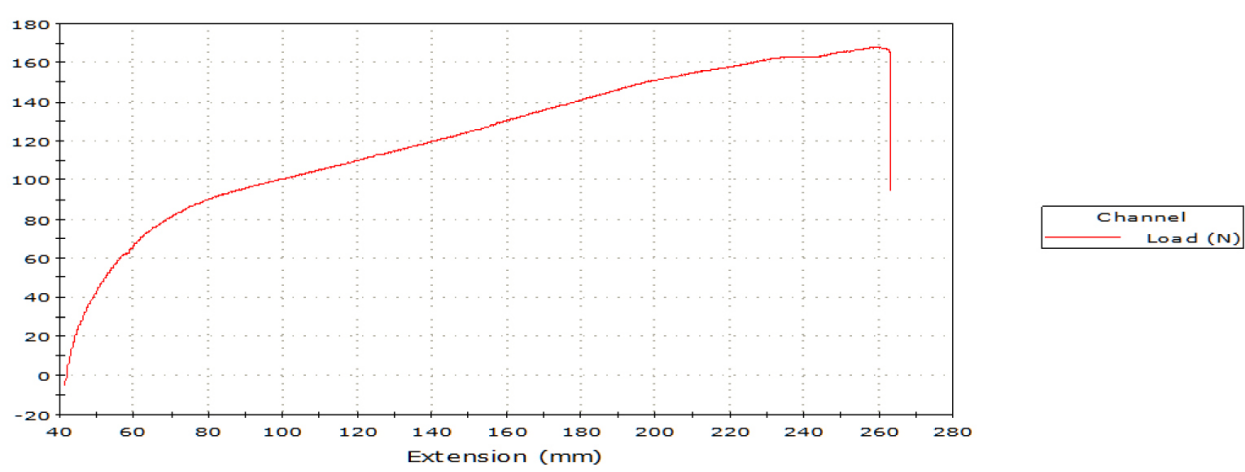

Graph 2. Extension vs load specimen for Selfix plastic sheet sticking them together

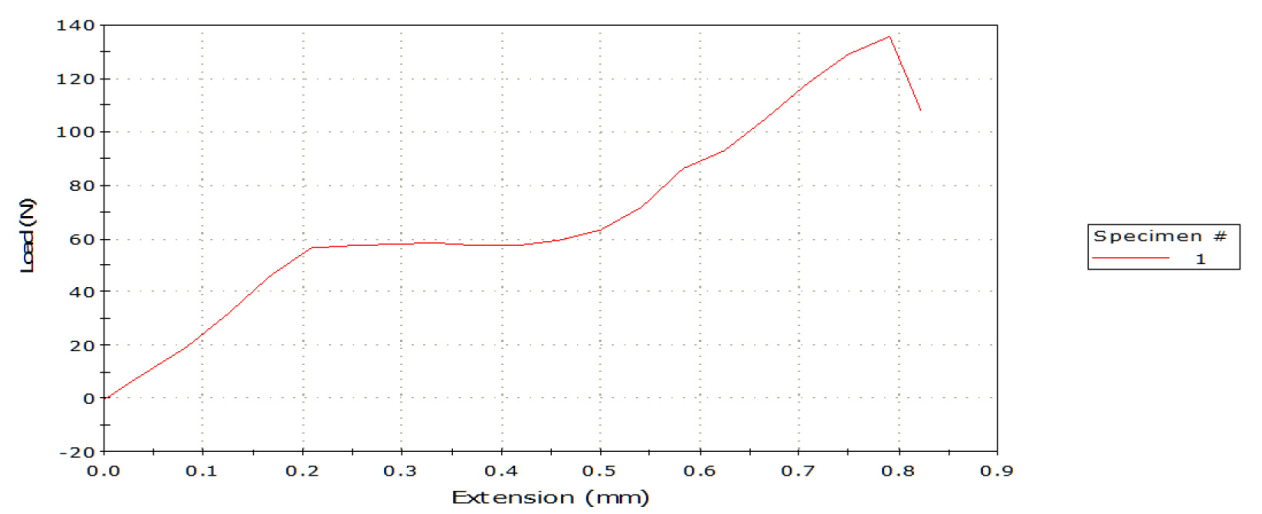

Graph. 3. Extension vs load specimen for Selfix plastic sheet with cardboard 
Table 1. Dimensions and mechanical properties of specimen for Selfix disk

\begin{tabular}{|c|c|c|}
\hline Specimen label & Thickness $(\mathrm{mm})$ & Width $(\mathrm{mm})$ \\
\hline Selfix plastic disk & 19.63000 & 20.00000 \\
\hline Length $(\mathrm{mm})$ & Area $\left(\mathrm{cm}^{2}\right)$ & Maximum Extension $(\mathrm{mm})$ \\
\hline 40.00000 & 3.92400 & 0.68079 \\
\hline Tensile stress at Maximum Extension $(\mathrm{MPa})$ & Maximum Load $(\mathrm{N})$ & Extension at Maximum Load $(\mathrm{mm})$ \\
\hline 0.22485 & 107.20584 & 0.62358 \\
\hline
\end{tabular}

Table 2. Dimensions and mechanical properties of specimen for Selfix plastic sheet sticking them together

\begin{tabular}{|c|c|c|c|}
\hline Specimen label & Width $(\mathrm{mm})$ & Area $\left(\mathrm{mm}^{2}\right)$ & Maximum load $(\mathrm{N})$ \\
\hline $\begin{array}{c}\text { Selfix plastic sheet which, } \\
\text { sticking together }\end{array}$ & 15.00000 & 6.00000 & 168.12 \\
\hline $\begin{array}{c}\text { Extension at } \\
\text { Maximum Load }(\mathrm{mm})\end{array}$ & $\begin{array}{c}\text { Tensile stress at } \\
\text { Maximum Load (MPa) }\end{array}$ & Modulus (E-modulus) (MPa) & Comment \\
\hline 259.40908 & 28.02070 & 41.03 & - \\
\hline $\begin{array}{c}\text { Load at Maximum Tensile } \\
\text { stress (N) }\end{array}$ & $\begin{array}{c}\text { Extension at Maximum } \\
\text { Tensile stress (mm) }\end{array}$ & $\begin{array}{c}\text { Extension at Break } \\
\text { (Cursor at break) }(\mathrm{mm})\end{array}$ & $\begin{array}{c}\text { Load at Break } \\
\text { (Cursor at break) }(\mathrm{N})\end{array}$ \\
\hline 168.12421 & 259.40908 & 76.57576 & 87.43249 \\
\hline
\end{tabular}

Table 3. Dimensions and mechanical properties of specimen Selfix plastic sheet with cardboard

\begin{tabular}{|c|c|c|}
\hline Specimen label & Thickness $(\mathrm{mm})$ & Width $(\mathrm{mm})$ \\
\hline Selfix plastic material & 10.00000 & 23.00000 \\
\hline Length $(\mathrm{mm})$ & Area $\left(\mathrm{cm}^{2}\right)$ & Maximum Extension $(\mathrm{mm})$ \\
\hline 43.00000 & 2.30000 & 0.82248 \\
\hline Tensile stress at Maximum Extension $(\mathrm{MPa})$ & Maximum Load $(\mathrm{N})$ & Extension at Maximum Load $(\mathrm{mm})$ \\
\hline 0.46972 & 135.60186 & 0.79157 \\
\hline
\end{tabular}
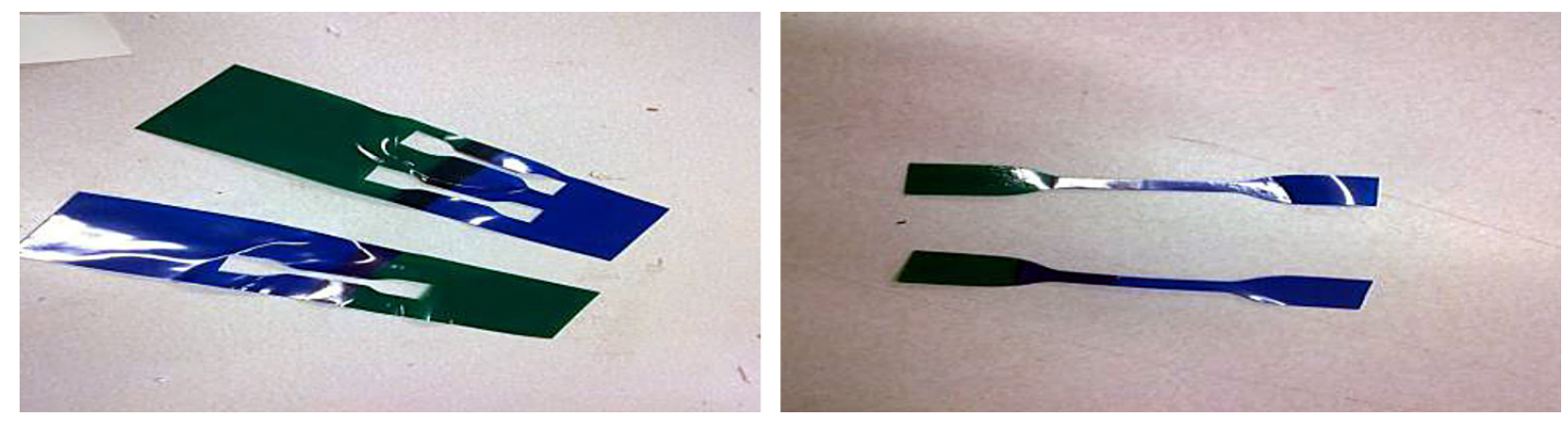

Fig. 7. Another specimen after remove from Selfix plastic sheet

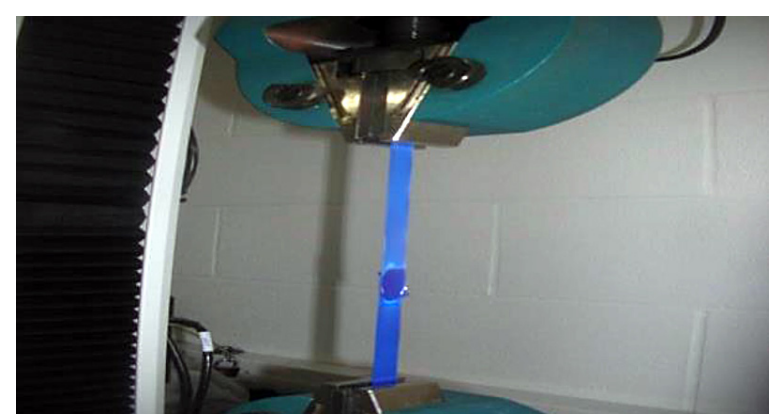

Fig. 8. Selfix plastic sheet pieces which sticking them together is $4 \%$ with $75 \%$ power. However, once tried in terms of manufacturability, the material started to melt and fuse. Because cutting with laser involves the concentration of high-density beams on the samples, excessive heat is generated upon the point of contact (Figure 12 show some shapes which were cut in different setting).

The Figure 13 represent the shapes created with laser and under different conditions. Among its other uses, Selfix appears in toys and other educational tools for children. With Corel Draw, 
a)

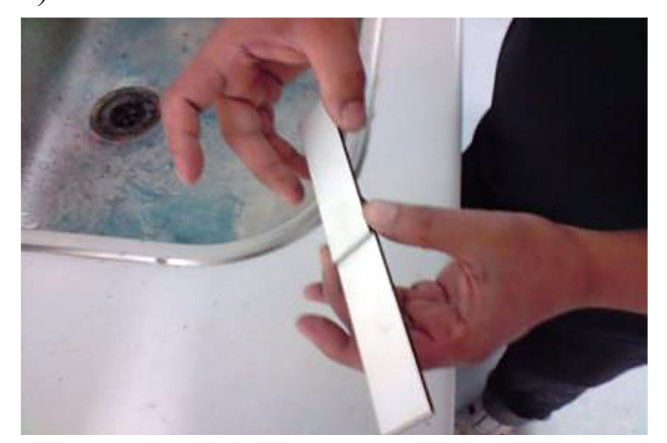

b)

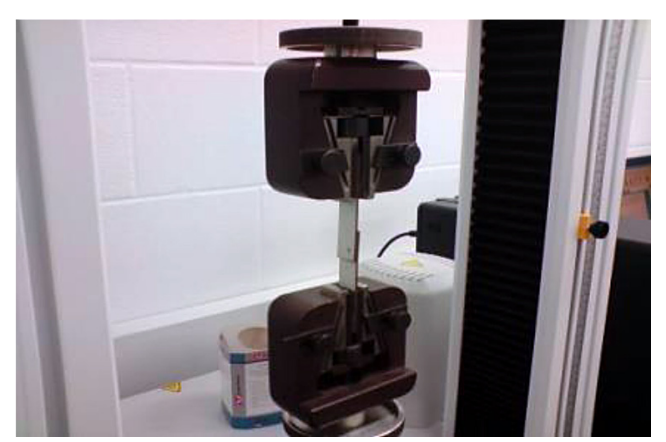

Fig. 9. a) Wetting the Selfix plastic to sticking with cardboard,

b) Specimen for Selfix plastic with cardboard in machine

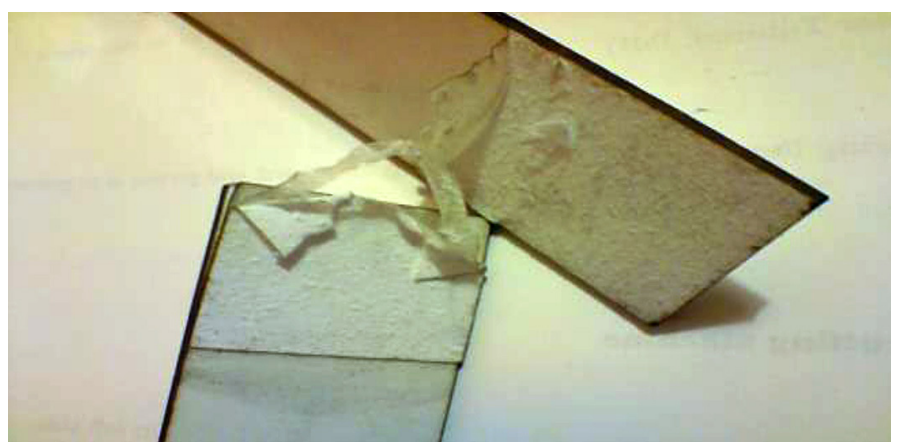

Fig. 10. Selfix did not break, in contrast to the cardboard (adhesion property for Selfix plastic)

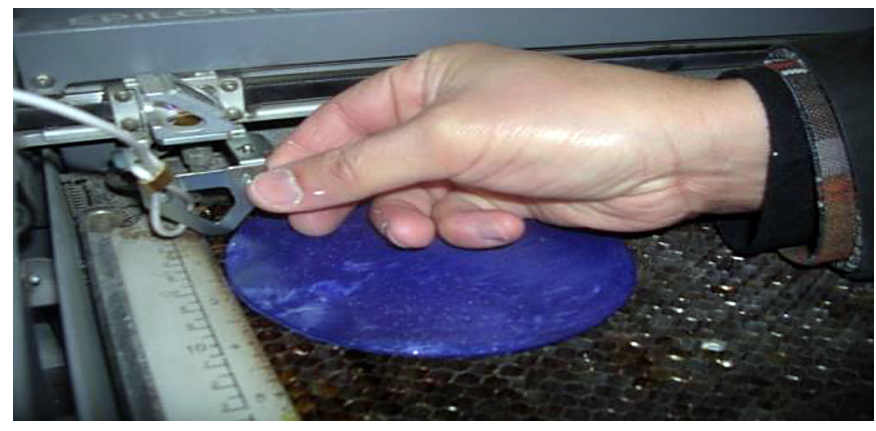

Fig. 11. Focusing gauge of laser cutting
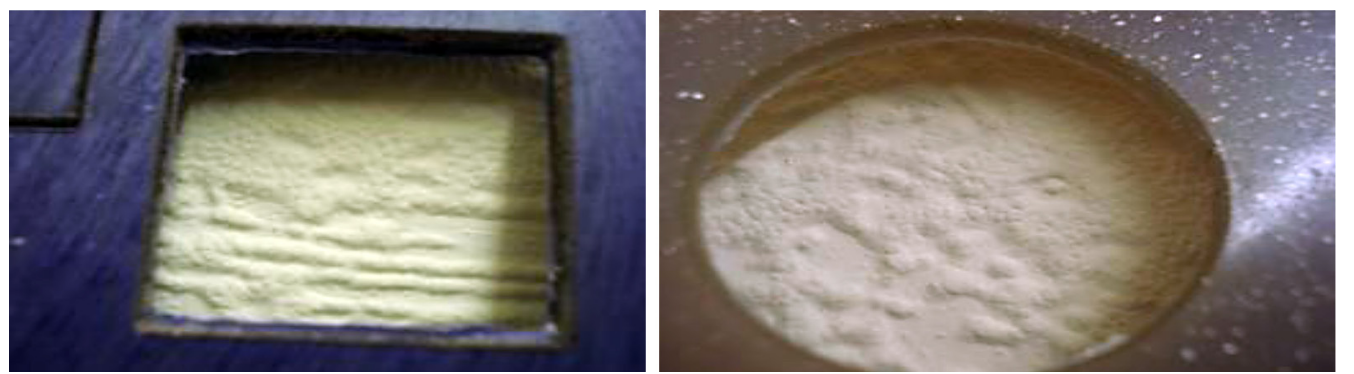

Fig. 12. Cut square shape and circle shape of Selfix plastic

such gear in different sizes were designed and cut with laser. In these gears, Selfix plastic can also serve as an adhesive to join parts for the transfer of motion from motor or pedal to any other part.

\section{Analysis of laser cutting results}

One has to note that laser may not be the best option to cut Selfix as the substrate can burn and, hence, necessitate further cleaning of 
a)

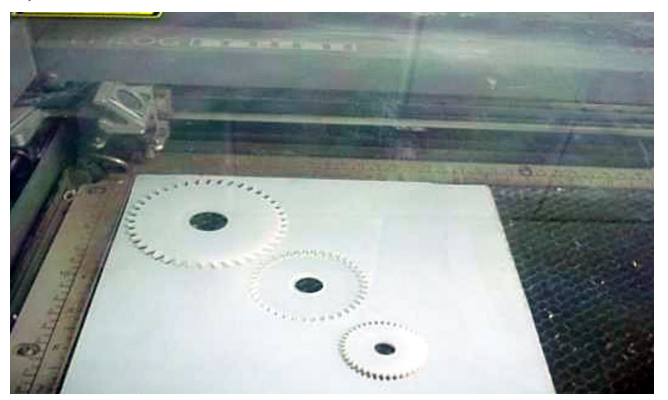

b)

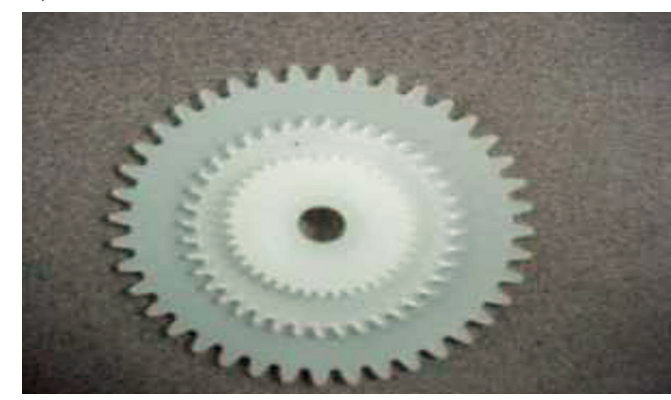

Fig. 13. a) Cutting gears from Selfix plastic by laser cutting,

b) Three gears stuck together by using the adhesion behaviour
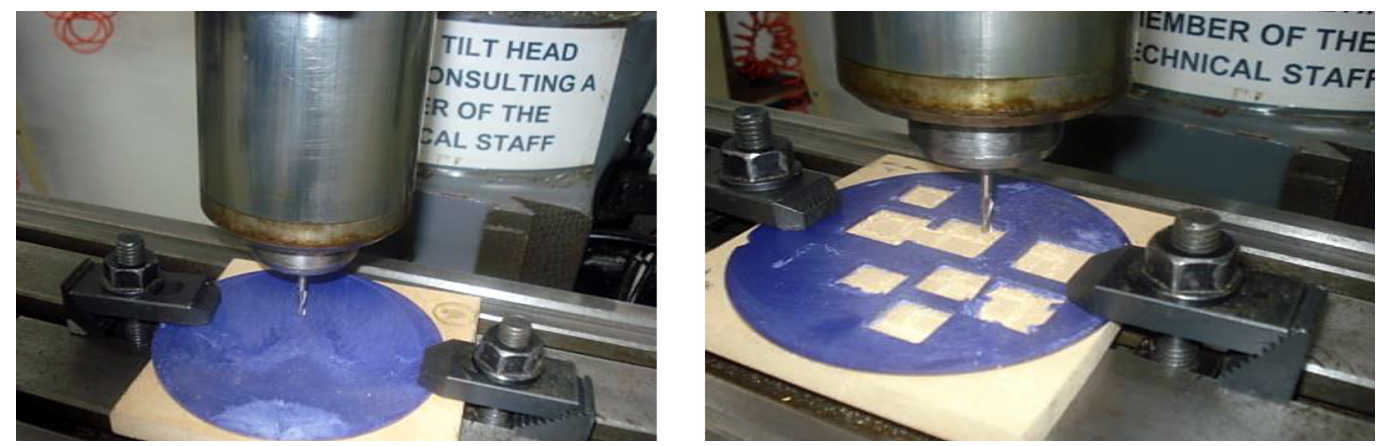

Fig. 14. The drilling in vertical position \& Selfix disk after cut
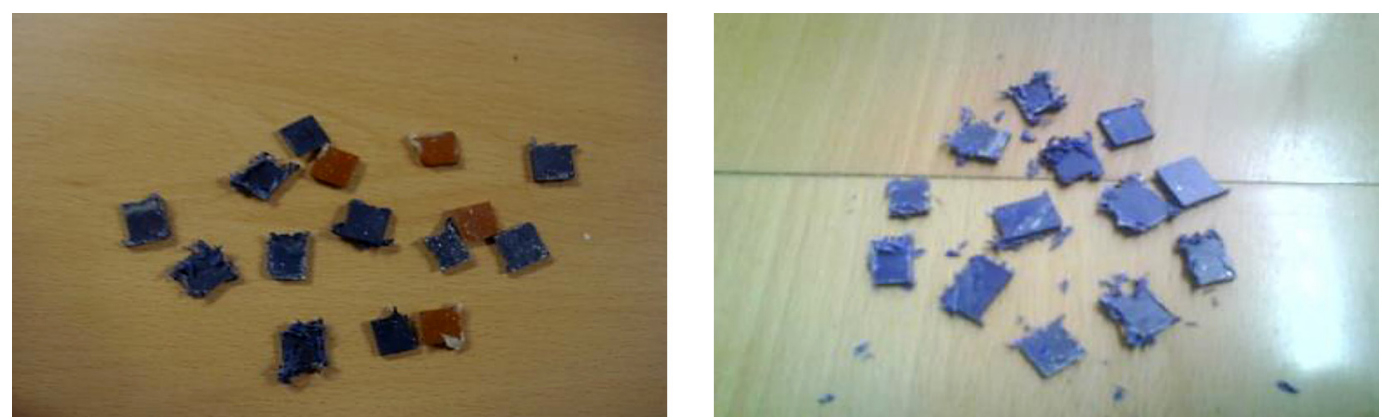

Fig. 15. Square shapes from selfix disk \& square shapes with dust

the edges before any later use. This is due to Selfix sheets being highly prone to heat, quickly melting as a result. For this reason, ideal sizes could not be achieved when cutting the piece, despite the ease of cutting itself. A less powerful beam was also tried and applied, but with no satisfactory outcome.

As to the Selfix disk, acceptable results were obtained in comparison to other sheet samples. Despite a repeated experiencing of burn on the disk, the resistance proved to be greater than in the sheet. Laser cutting went smoothly, with reduced time to manufacture due to speedy shaping of the profile. The disk sample was more workable due to particle distribution and bonding being robust and uniform in comparison to the sheet sample. Another highlight during this process was that no dust was formed and the tool remained stable regardless of the machining speed, thus enabling safe and clean operations.

\section{Results of milling machine on selfix material}

Milling was applied to the Selfix material to cut shapes, which were later compared to those cut by laser. For this purpose, the surface roughness was assessed using an SEM.

The Figures 14 and 15 show the square shapes formed using a milling machine with proper feed rate used in the workshop. 


\section{Analysis of the milling results}

It was observed that while cutting Selfix by a milling machine, the substrate material was deformed on the surface and, hence, needed to be removed from the edges on the Selfix material. The milling operations were also applied and tested on the Selfix disk, which caused the entire machine to shake due to its hardness. In addition, cutting at higher speeds generated a lot of heat within the contact zone between the tool and the work piece. Dust was also formed as a result of milling.

Under normal conditions, coolants are applied to reduce heat within the contact zone; yet, given the biodegradable nature of this polymer, such an application could result in sticking of the piece to the work bench or other unanticipated formations. This limitation makes cutting Selfix even more challenging.

The samples made during the research were found to have satisfactory surface finish and pleasant appearance. Above all, the amount of time spent to produce them was much less than in the case of other materials. It can be stated that combining Selfix with calcium carbonate can be a useful way to reduce the operation time.

\section{Results of surface roughness measurement}

In the lab, many points were marked on the Selfix surface after cutting. The process to measure surface roughness was carried out with a stylus-type instrument in order to examine the texture. The Figure 16 show the stylus measurements for the points marked for laser cutting as well as those for milling.

a)

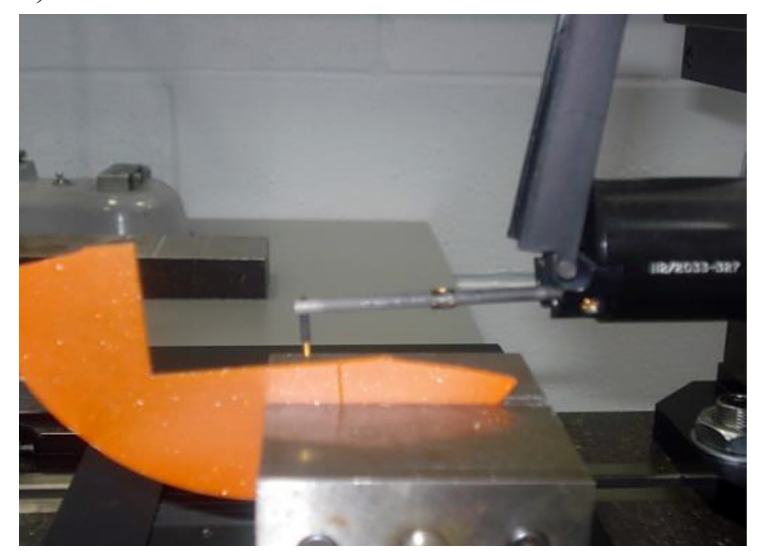

The following measurement parameters were applied in this work:

- Ra: Roughness average

- Rz: (DIN) Mean peak-to-valley height

- Rz: (ISO) Ten point height

- Rmax: Maximum peak-to-valley height

- Rt: Vertical height between max/min

- Ry: Maximum roughness depth

- Rq: RMS of roughness average

- Rp: Maximum peak height

- Ssk: Skewness

- Kku: Kurtosis

- Rq: calculated by taking the root mean square in the series of measurements of deviations from the centerline; and

- Rz: the average of the five highest and the five deepest valleys within the sampling length, measured from a line parallel to the mean line.

The results are commonly obtained from the graphs; however, in lab settings, these calculations are conducted by the computer. The Graphs 4-7 show us how measure many points for surface of the Selfix material. First point for Selfix by milling machine.

\section{Selfix milled sample}

For surface roughness, the amplitudes of peak were investigated. If the graph appears in a straight line, it means that the surface is smooth. However, these graphs reveal large amplitudes of peaks, indicating roughness.

Graph 4 shows milled surfaces along the thickness at position one.

b)

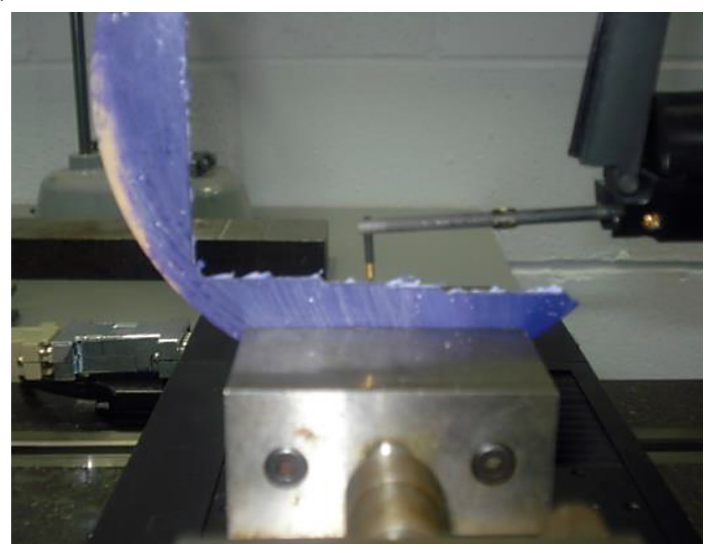

Fig. 16. a) The stylus measurement the points for laser cutting,

b) The stylus measurement the points for milling machine 


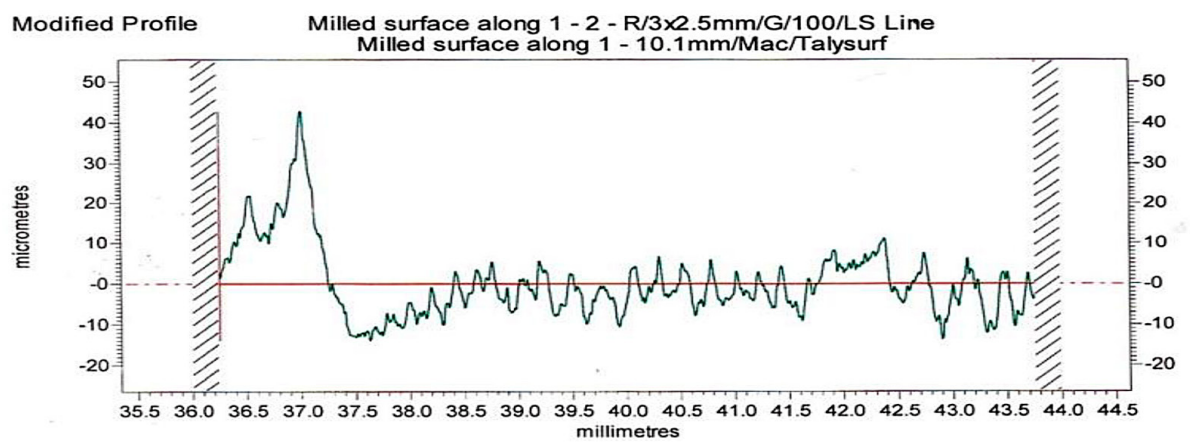

Graph. 4. Surface roughness at first point for milling machine: Ra $6.2633 \mu \mathrm{m}$ Rp $1 \max 42.8392 \mu \mathrm{m}$ Rv $1 \max 13.9342 \mu \mathrm{m}$ Rt $56.7735 \mu \mathrm{m}$ Rp $20.2148 \mu \mathrm{m}$ Rv $12.7285 \mu \mathrm{m}$ Rz(DIN) $32.9433 \mu \mathrm{m}$ RS $178.72 \mu \mathrm{m}$ RSm $576.92 \mu \mathrm{m}$

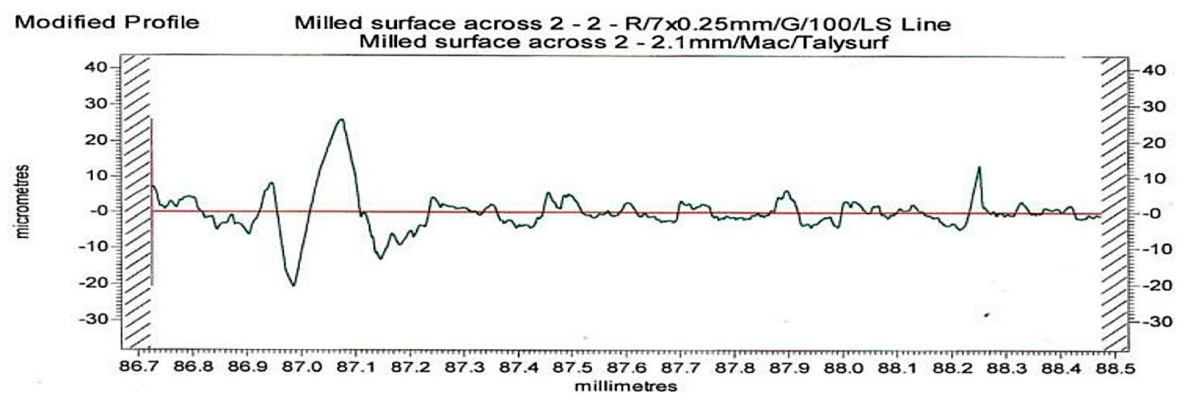

Graph. 5. Surface roughness at second point for milling machine: Ra $3.4600 \mu \mathrm{m}$ Rp $1 \max 26.0129 \mu \mathrm{m}$ Rv $1 \max 20.6561 \mu \mathrm{m}$ Rt $46.6690 \mu \mathrm{m}$ Rp $9.6734 \mu \mathrm{m}$ Rv $8.2705 \mu \mathrm{m}$ Rz(DIN) $17.9438 \mu \mathrm{m}$ RS $55.29 \mu \mathrm{m}$ RSm $215.29 \mu \mathrm{m}$

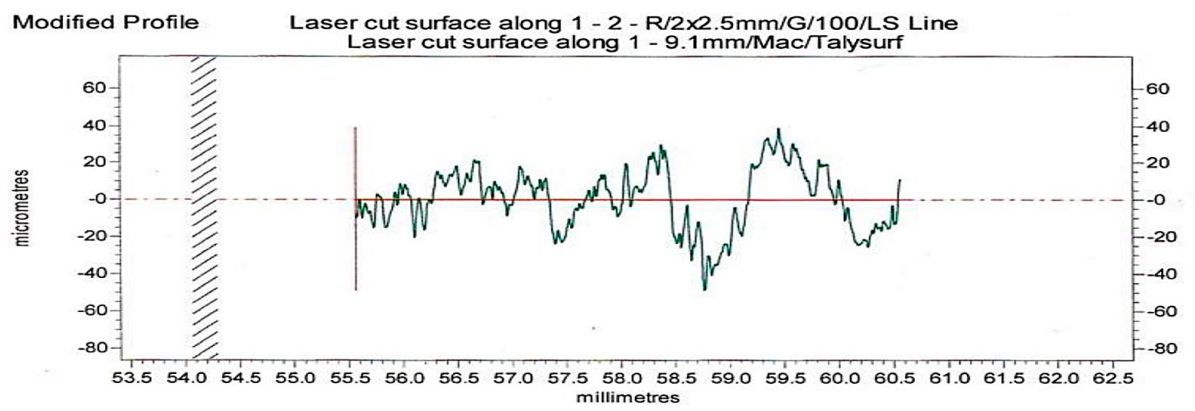

Graph. 6. Surface roughness at first point for laser cutting: Ra $13.1081 \mu \mathrm{m}$ Rp 1max 39.3216 $\mu \mathrm{m}$ Rv $1 \max 48.7201 \mu \mathrm{m}$ Rt $88.0416 \mu \mathrm{m}$ Rp $30.3790 \mu \mathrm{m}$ Rv 36.3858 $\mu \mathrm{m} \mathrm{Rz(DIN)} 66.7648 \mu \mathrm{m}$ RS $119.30 \mu \mathrm{m}$ RSm $764.83 \mu \mathrm{m}$

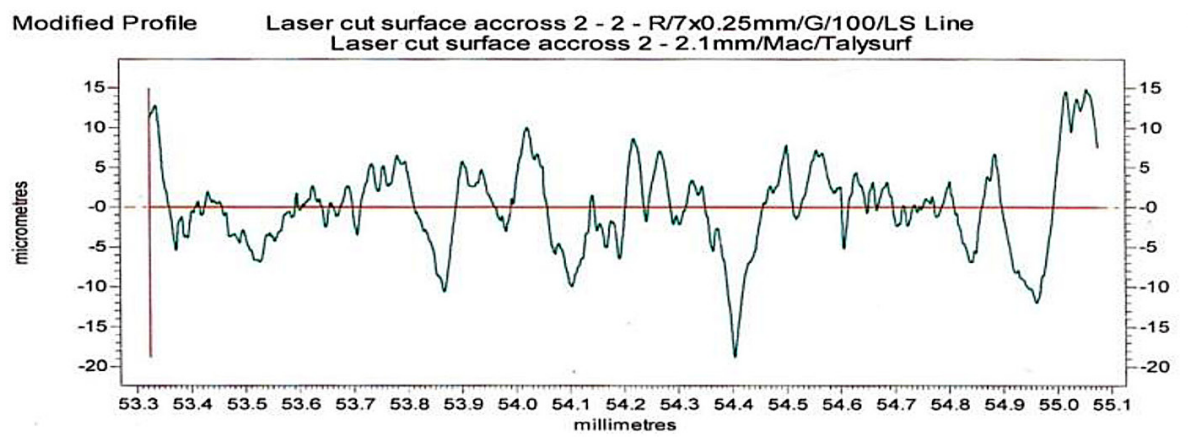

Graph. 7. Surface roughness at second point for laser cutting: Ra $4.0921 \mu \mathrm{m}$ Rp 1max $14.9212 \mu \mathrm{m}$ Rv 1 max $18.7721 \mu \mathrm{m}$ Rt $33.6932 \mu \mathrm{m}$ Rp $9.3429 \mu \mathrm{m}$ Rv $9.5427 \mu \mathrm{m}$ Rz(DIN) $18.8855 \mu \mathrm{m}$ RS $48.59 \mu \mathrm{m}$ RSm $119.05 \mu \mathrm{m}$ 


\section{More milled surfaces}

These surfaces are related to the other side of the cutter. Given the lower levels of vibration here, the surface appears to be much smoother across the thickness at position two (Graph 5).

\section{Laser-cut samples}

We attempted to apply $0.8 \mathrm{~mm}$ and 0.25 filters, but achieved no satisfactory results. Moreover, there is a disadvantage in using 2.5 filter, in that it takes away too much of the traverse length. The evaluation length is a multiple of the filter or sample length. As a $2.5 \mathrm{~mm}$ filter was applied, the measurement was $7.5 \mathrm{~mm}$ long over a $10 \mathrm{~mm}$ traverse length. With only $9 \mathrm{~mm}$ available, the length will be $0.5 \mathrm{~mm}$.

Laser surfaces (along the thickness at position one) - Graph 6 .

The edge is at an angle, which makes it necessary to approximately align the machine to it across the thickness at position two (Graph 7).

As per the results, one can obtain the approximate average maximum profile as the difference between the heights of the ten highest peaks and the ten deepest valleys. This shows us the surface texture on limited-access areas having either high peaks or low valleys.

a)

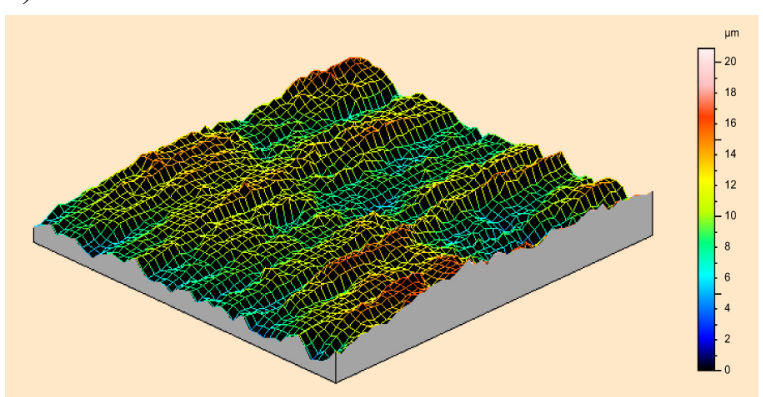

A datum marked on the surface allows for the precise location of the surface $3 \mathrm{D}$ maps and $2 \mathrm{D}$ surface profiles to be accurately pinpointed, thus allowing us to compare the parent surface and replica.

Figures 17-20 show meshed axonometric and photo simulation as well as a pseudo-colour Image for the surface of Selfix material after cutting with a milling machine and laser.

\section{Analysis of surface roughness measurement results}

As per the cutting effect on the Selfix surface according to the graphs, the specimen roughness was found to vary depending on the location. For instance, at the first point for milling machine, the surface roughness stands at $6.26 \mu \mathrm{m}$ and at the second point, $3.46 \mu \mathrm{m}$. In the case of laser cutting, this value at the first point is $13.10 \mu \mathrm{m}$ and $4.09 \mu \mathrm{m}$ at the second point. Upon comparison, the laser-cut surfaces reveal more roughness in contrast to the milling machine, and can also be compared between the average for value of surface roughness at these points.

The average for milling machine:

$$
\frac{6.26+3.46}{2}=4.86 \mu \mathrm{m}
$$

b)

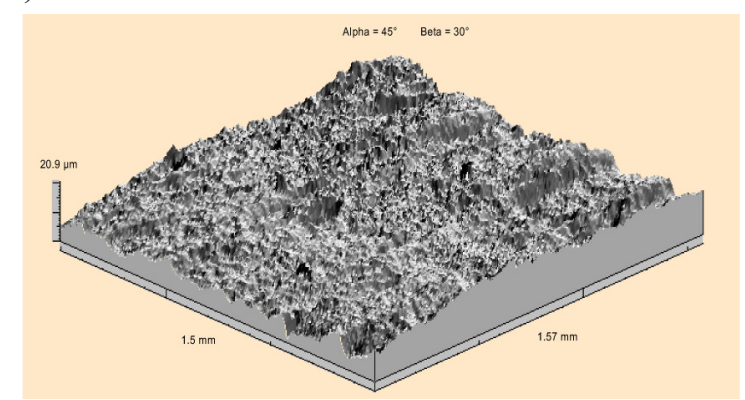

Fig. 17. Selfix milled sample: a) Meshed axonometric at point for milling machine,

b) Level of surface photo simulation at point for milling machine
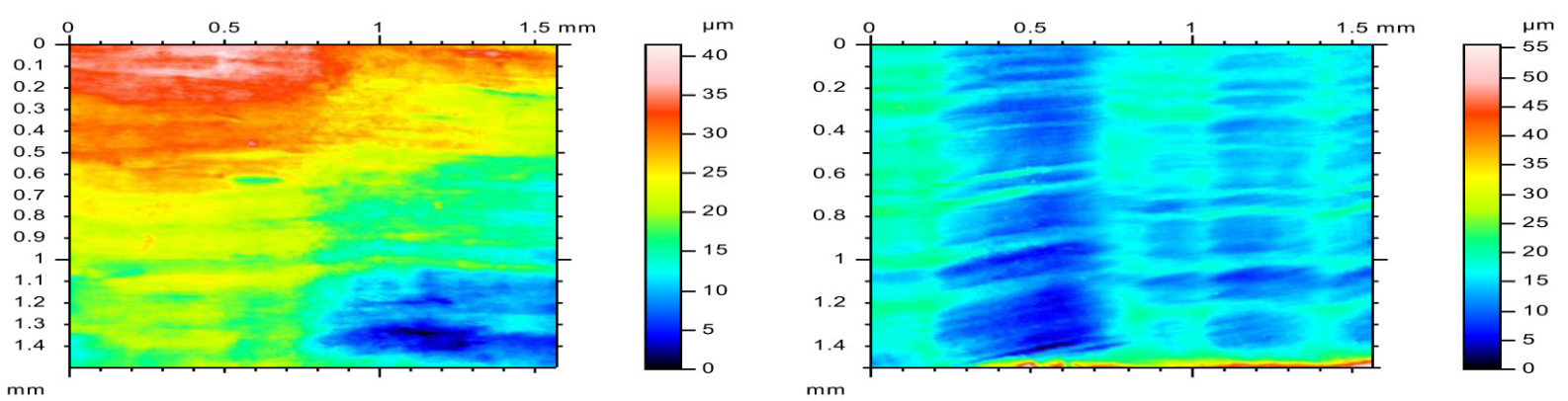

Fig. 18. Pseudo colour image at point for milling machine 
a)

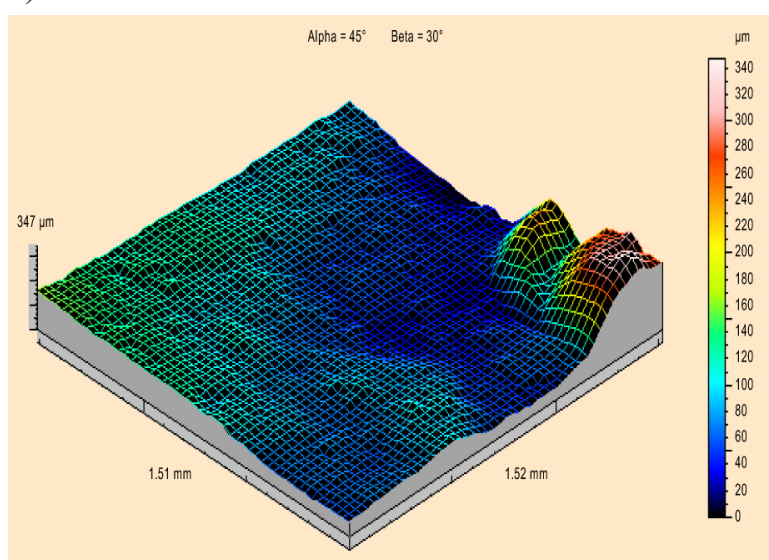

b)

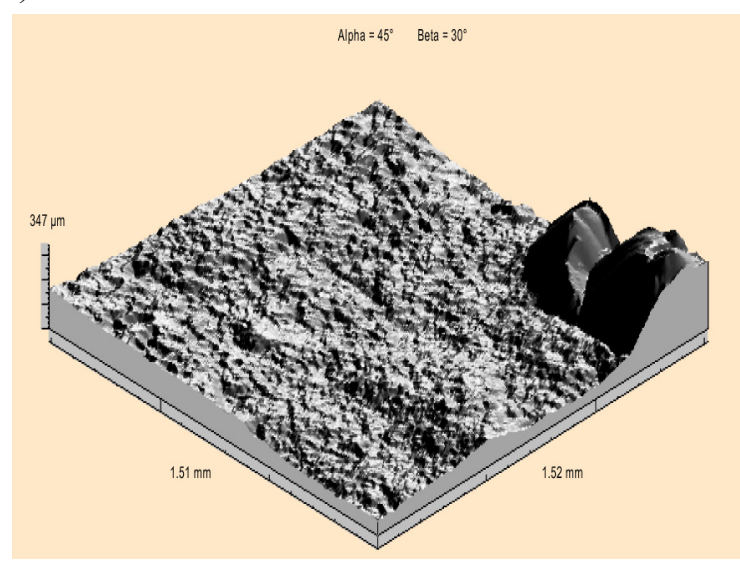

Fig. 19. Selfix laser cut sample (position $2 \& 3 \mathrm{D}$ scan): a) Meshed axonometric at point for laser cutting, b) Level of surface photo simulation at point for laser cutting
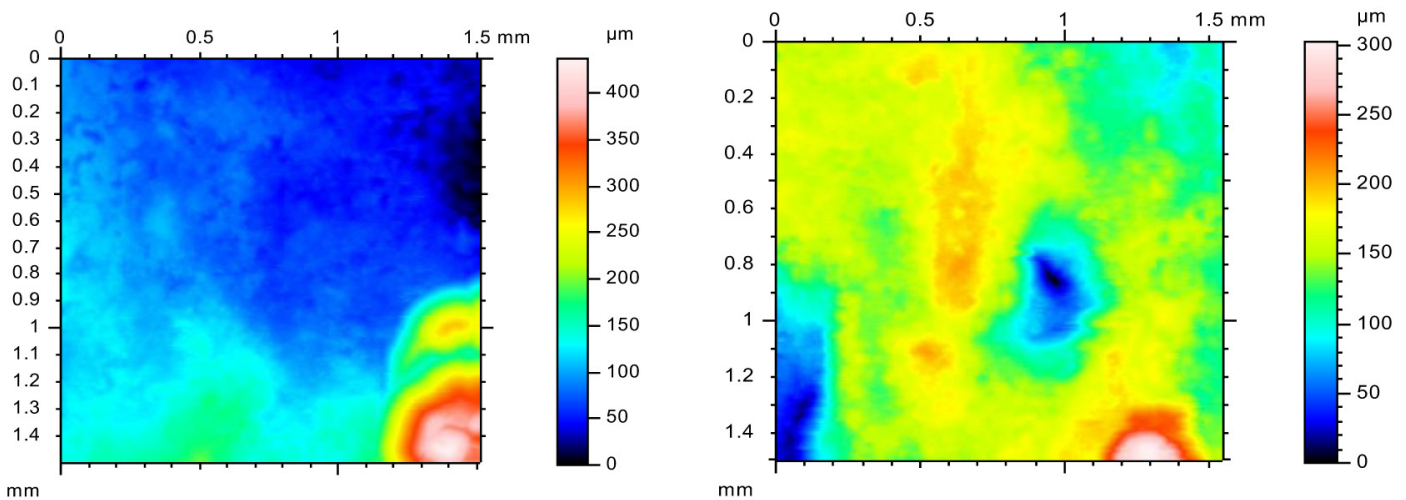

Fig. 20. Pseudo colour image at point for laser cutting

The average for laser cutting:

$$
\frac{13.10+4.09}{2}=8.59 \mu \mathrm{m}
$$

The results show greater roughness on the surface cut by laser. Apart from this, the images for meshed axonometric, photo simulation and pseudo color reveal the signs of melting at the strength joint surface. It can be concluded that the burns by laser cutting or deformation by milling machine on the surface of Selfix material need to be addressed to achieve better and higher-strength surface quality. The surface roughness model is based on mechanical analysis, and hardness and surface deformation depend on the type of material.

The surface roughness is useful in determining the quality of the bond of the polymer with other materials. The type of bonding is an essential factor that influences the physical, mechanical and aesthetics of the substance. A composite is a kind of engineered material that consists of particular fillers in a soft matrix. Here, the matrix material is Selfix and filler material used for enhancing properties is calcium carbonate. It was found that the quality of the bond improves with a decrease in the filler material. The reason behind this improvement is the covalence, and the bonding between the molecular chains of the polymer and material molecules when they come into contact.

\section{Scanning electron microscope results}

According to the SEM observations, images were taken from the structure of the Selfix sample on the cut edges in order to accurately determine the particle distribution (Figure 21). On the basis of the results, it was found that Selfix contains other compounds. Other images, taken to capture the microstructural features, appear in the following for three different materials on the cut edges.

\section{Analysis of sem results}

From the images captured with the SEM, one can see that pure Selfix looks well as regards the 
a) Material - Selfix blended with Calcium Carbonate:

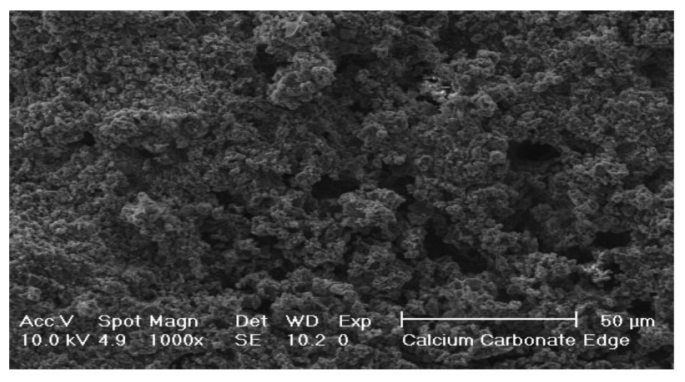

Image 1.at $1000 \mathrm{x}$

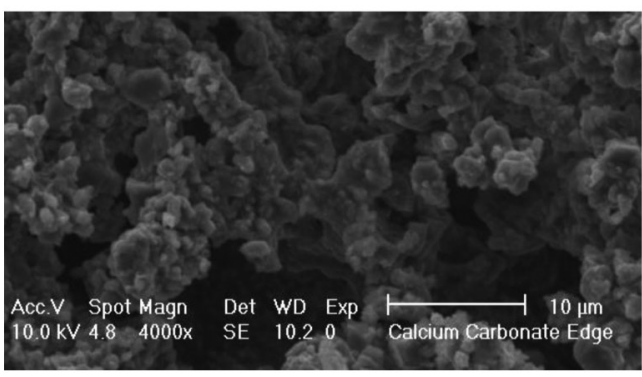

Image 2 at $4000 x$

b) Material -Selfix blended with wood flour.

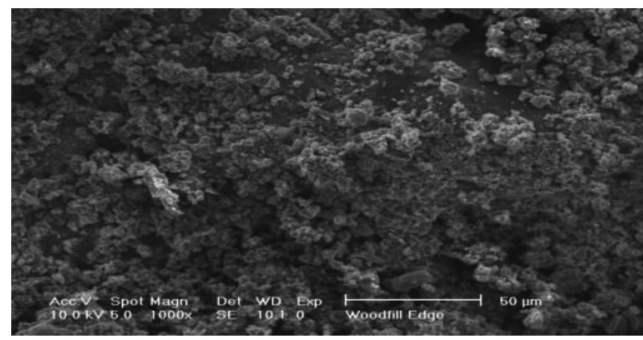

Image 3 at $1000 \mathrm{x}$

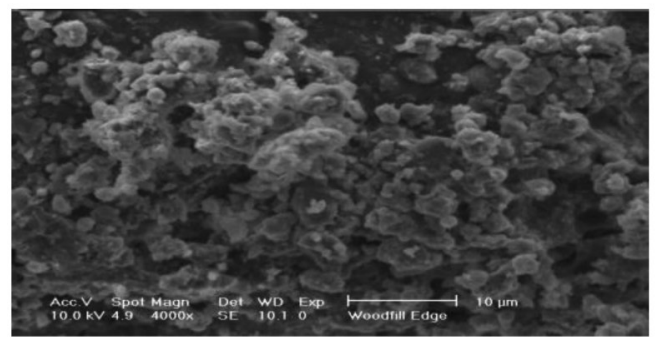

Image 4 at $4000 x$

c) Material - Pure selfix with green pigment.

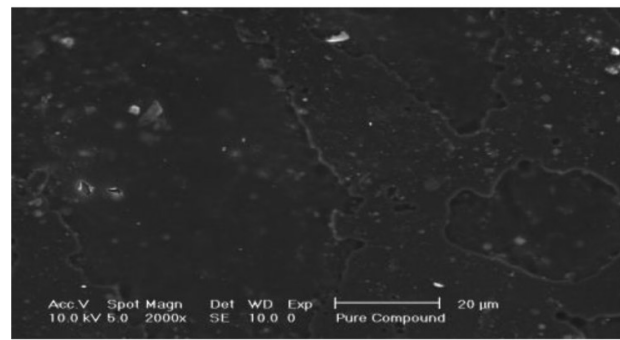

Image 5 at $2000 \mathrm{x}$

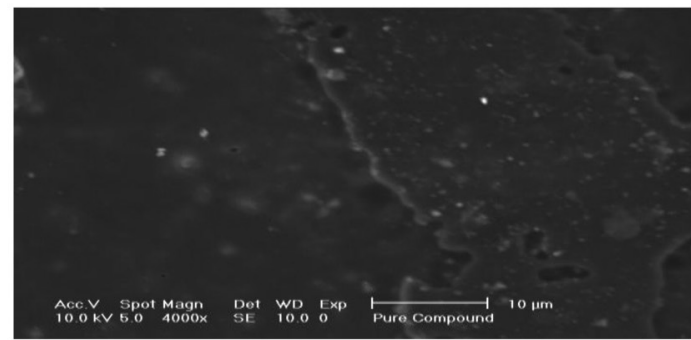

Image 6 at $4000 x$

Fig. 21. Structure of the Selfix sample

material uniformity, but once it is blended with fillers such as calcium carbonate, uniformity decreases as a result of pores formed during molding, Other factors having impact on uniformity include selecting inappropriate die in the extrusion machine, wrong temperature settings during the extrusion process, and improper mixing or combination with fillers. All of these can cause particle distribution to become coarse in the case of biodegradable materials.

Apart from this, it was observed that calcium carbonate and wood flour go well in combination with Selfix and produce an acceptable mix, satisfactory surface finish, and also added tensile strength. Otherwise, wood fillers are not mixed properly with the Selfix material matrix, wood traces can appear unevenly scattered all over the base material. For this reason, this filler is not a proper choice to go with Selfix when it comes to machining. Specifically, common productions processes, namely turning grinding, can generate high amounts of wood powder, thus increasing the health and safety hazards at the same time.

Considering that wood is a good heat conductor, laser cutting burns these particles, creating flame and fume, leading to possible damage to the entire setup or any part of the machine. As these machines are costly to purchase and maintain, from the manufacturing and economic perspective it is not quite logical to make biodegradable 
a) Material Sample: - Selfix blended with Calcium Carbonate.

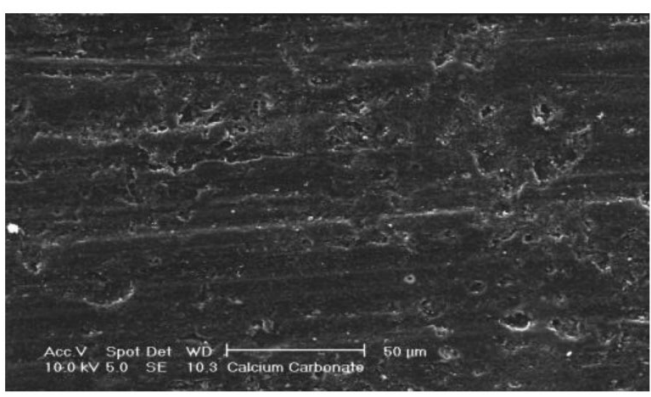

Image 7 at $1000 x$

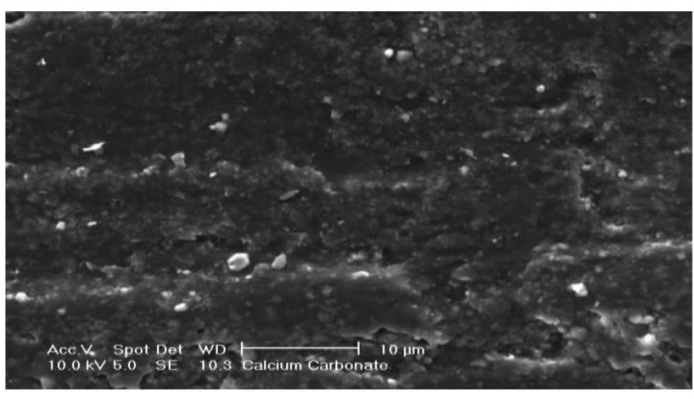

Image 8 at $4000 x$

b) Material Sample: - Selfix blended with Wood.

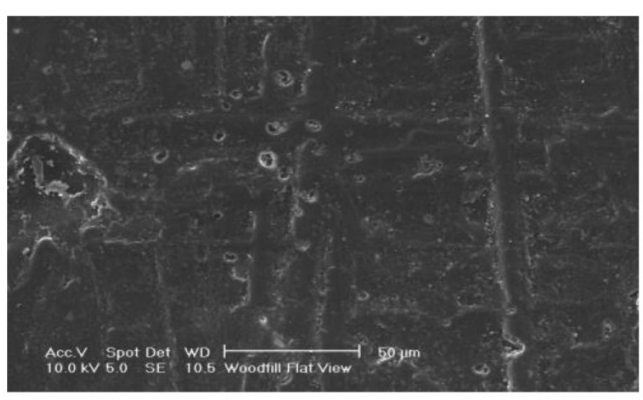

Image 9 at $1000 \mathrm{x}$

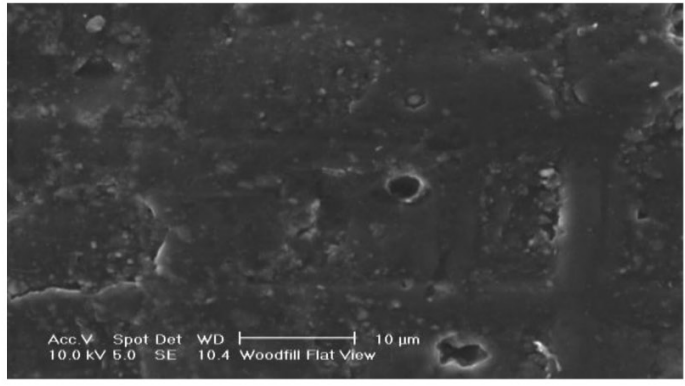

Image 10 at $4000 x$

c) Material Sample - Pure Selfix with green pigment.

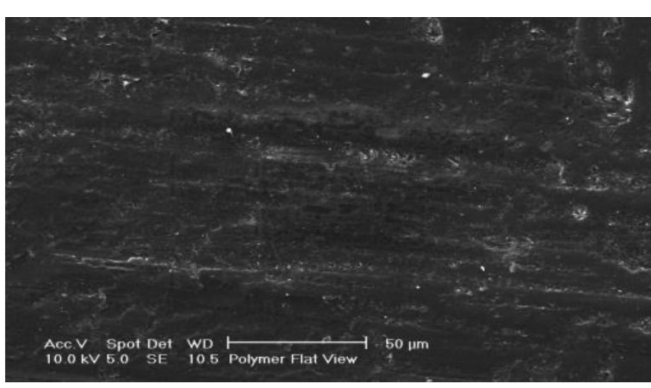

Image 11 at $1000 \mathrm{x}$

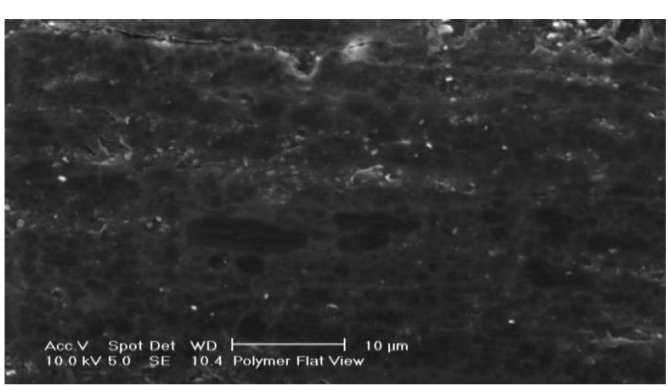

Image 12 at $4000 x$

Fig. 22. SEM images of sample material on the surfaces

material in this way. Another disadvantage of the wood-blended Selfix is that, once wet, it takes much longer to stick and forms rather weak bonds when compared to the other two biodegradable polymer samples. In conclusion, it can be stated that Selfix in combination with wood is not manufacturing-friendly.

\section{Benefits of innovation with smart material}

Selfix offers the specific benefits of making models quickly as well as prototyping, Apart from these, it has found applications in automata to produce countless shapes and forms, some of which would not necessitate other material to be used with Selfix. Given its self-adhesion quality, it can stick to different materials simply by means of wetting. In the case of educating children, this material can be very useful for many creative activities and also making toys. This can help families in economizing on educational gadgets, helping children to grow more imaginatively by, perhaps, materializing their own ideas into shapes, and even getting the parents involved in activities. 
There is no question that Selfix helps with creativity and creates more entertainment while learning. These benefits aside, the disposal of paper and cardboard can be reduced. Selfix can also be applied in making products with added value, or at home to make designs without worrying about waste and toxicity.

\section{Selfix material (biodegradable polymer) as adhesive}

In most cases, the main factor in selecting adhesives is their bond quality and the ability to undertake mechanical loading. Another factor is the status of the contact surfaces and its preparation by etching, priming and grinding to remove coarse material, dirt, and grease gathered which can adversely affect the bond strength. These processes take time and require other resources [19].

In this respect, as Selfix was designed to be water-soluble, the free molecules within the material make strong joints with others when drying, thus making Selfix an adhesive in some cases. Apart from this, a thin layer of this material can increase the axial stress resistance against tensile and compressive loading. Another use is improved bonding since almost all the available surface area can be contacted and holes and air pockets avoided. A smooth surface hosts far more free molecules, which ensure proper adhesion, compared to an uneven one [20].

\section{CONCLUSION}

Numerous companies are attempting to reduce their carbon footprint by decreasing it in favor of environmental benefits. With this in mind, paper and cardboard can be reused and not disposed of. The present research suggests that Selfix material could be the solution for reusing paper and cardboard and, hence, saving energy and natural resources needed to produce them. Using Selfix to reuse paper and cardboard waste would be beneficial both environmentally and economically, especially in the case of families and, within a larger scale, businesses.

Certain countries, such as the UK, have passed the regulations targeting waste, $\left(\mathrm{CO}_{2}\right)$ emission, re-using, and recycling. In line with these efforts, and given the biodegradability of Selfix smart material, it can have a role in governments and environmental groups' initiatives toward environmental preservation.
Finally, it can be stated that Selfix has numerous novel applications for different purposes in education and business. The following may be recommended based on this research outcomes:

- Supporting industrial companies and enterprises that aim at reducing waste, such as Selfix Technology Company;

- Encouraging collaboration between the sector and universities to create the solutions targeting product improvement to reduce the environmental impacts;

- Improving the knowledge transfer capacity and skills in innovative product development in public research organisations along with the measures to promote such awareness and skills among students;

- Encouraging the production of packing material that is eco-friendly and re-useable;

- Conducting further research on Selfix properties for further improvement and 3D modelling to design novel products and shapes; and

- Concentrating on case studies related to waste reduction to find other applications for Selfix and biodegradable materials to that end.

\section{REFERENCES}

1. Monte M.C., E. Fuente A. Blanco and C. Negro, (2008). Waste management from pulp and paper production in the European Union, 293 (308).

2. Chandra R. (2015). Environmental Waste Management, 1st Edition, pp. 586.

3. Reuter M., E. Worrell (2014), Handbook of Recycling, pp. 600.

4. Ghosh S.K. (2016) Waste Management and Resource Efficiency. Proceedings of 6th IconSWM 2016, Springer.

5. Squsihy plastik, heat shape mould (2018). Access: http://selfixtechnology.com/.

6. Kalamdhad A.S., J. Singh, K. Dhamodharan (2016). Advances in Waste Management, Select Proceedings of Recycle, Springer.

7. Freiman S.W., J.J. Mecholsky Jr. (2012), The fracture of brittle materials: Testing and analysis, pp. 196.

8. Kaufmann E.N. (Ed.) (2012), Characterization of Materials, 2nd Edition. Wiley \& Sons, Inc., pp. 2438. DOI: $10.1002 / 0471266965$.

9. Davis J..R. (2004), Tensile Testing, 2nd Edition, pp. 283, ASM International.

10. Yilbas B.S. (2017), The Laser Cutting Process 
(Analysis and Applications), 1st Edition, pp. 328.

11. Bowman M. (2015) CNC Milling in the Workshop (Crowood Metalworking Guides), Kindle Edition, pp. 144.

12. Rattat Ch. (2017), CNC Milling for Makers: Basics - Techniques - Applications, Paperback, Kindle Edition.

13. Poon C.Y., B. Bhushan, (1995) Comparison of surface roughness measurements by stylus profiler, AFM and non-contact optical profiler, Wear, 190(1), 76-88.

14. Balamurugan R., S. Muruganand, (2015) Study of surface roughness by stylus profilometer and binary laser speckle B/D counting techniques, International Journal of Advanced Research in Electrical, Electronics and Instrumentation Engineering, 4(5).

15. Lee D.H. (2013) 3-Dimensional profile distortion measured by stylus type surface profilometer. Mea- surement 46(1), 803-814.

16. Mattsson L., P. Wagberg, (1993) Assessment of surface finish on bulk scattering materials: A comparison between optical laser stylus and mechanical stylus profilometer. Precision Engineering, 15(3), 141-149.

17. Nellist P.D., S.J. Pennycook, (2011) Scanning Transmission Electron Microscopy. Springer Science, pp. 762.

18. Goldstein J., D.E. Newbury, P. Echlin, D.C. Joy, A.D. Romig Jr., C.E. Lyman, C. Fiori, E. Lifshin (2012), Scanning Electron Microscopy and X-Ray Microanalysis, Springer Science, pp. 762.

19. Pocius A.V. (2012), Adhesion and Adhesives Technology, An Introduction, 3rd Edition, pp. 386.

20. Ebnesajjad S., A.H. Landrock (2015) Adhesives Technology Handbook, 3rd Edition, pp. 432. 